\title{
O estímulo ao diálogo colaborativo a partir de tarefas baseadas em corpus: uma experiência no ensino de italiano/LE
}

\author{
Graziele Frangiotti \\ Universidade de São Paulo \\ grazielefrangiotti@gmail.com
}

\begin{abstract}
RESUMO: Neste trabalho é discutido o papel da interação em sala de aula de língua italiana/LE a partir de tarefas construídas com dados provenientes de corpus. Como pressupostos teóricos, trabalhamos, sobretudo, com os conceitos de tarefa (Ellis, 2009), bem como com as noções de diálogo colaborativo e languaging, cujas bases fundamentais se ancoram na teoria sociocultural vygotskyana, mas que encontram respaldo mais recente nos trabalhos de Swain $(2005,2006)$ e Figueiredo (2019). Do ponto de vista prático, a pesquisa examina os áudios e as transcrições de interações de 11 aprendizes de nível B1 que frequentaram um curso de extensão na Universidade de São Paulo ao longo do segundo semestre de 2017. Como resultados principais, observamos que as tarefas propiciaram o aparecimento de processos conectivos complexos, como o noticing, o teste de hipótese, o scaffolding, entre outros, o que nos permitiu avançar a hipótese de que essas atividades promoveram o diálogo significativo e, por conseguinte, a produção de languagings que contribuem decisivamente para a construção do conhecimento da língua estrangeira.
\end{abstract}

Palavras-chave: Ensino de língua italiana/LE. Tarefa. Corpus linguístico. Diálogo colaborativo. Interação.

ABSTRACT: In questo lavoro viene discusso il ruolo dell'interazione nell'aula di lingua italiana/LS a partire dalla proposizione di task costruiti sulla base di dati provenienti da corpus. Come presupposti teorici, lavoriamo, soprattutto, con i concetti di task (Ellis, 2009), così come con le nozioni di dialogo collaborativo e languaging, le cui basi si fondano sull'approccio socioculturale di Vygotskij, ma che di recente trovano supporto nelle riflessioni di Swain $(2005,2006)$ e Figueiredo (2019). Da un punto di vista pratico, la ricerca prende in esame le registrazioni audio e le trascrizioni di interazioni tra 11 apprendenti di livello B1 che hanno frequentato un corso presso l'Università di San Paolo durante la seconda metà del 2017. Come risultati centrali, abbiamo osservato che $\mathrm{i}$ task hanno stimolato processi cognitivi complessi come il noticing, la verifica di ipotesi e lo scaffolding, il che ci ha consentito di avanzare l'ipotesi secondo cui queste attività favoriscono il dialogo e, di conseguenza, la produzione di languagings che contribuiscono alla costruzione della conoscenza in lingua straniera. : 
Parole chiave: Insegnamento di italiano/LS. Task. Corpus linguistico. Dialogo collaborativo. Interazione.

ABSTRACT: In this work, the role of interaction in the Italian language / LE classroom is discussed, based on tasks constructed with data from corpus. As theoretical assumptions, we work, above all, with the concepts of task (Ellis, 2009), as well as with the notions of collaborative dialogue and languaging, whose fundamental bases are anchored in Vygotskian socio-cultural theory, but which find more recent support in the works of Swain $(2005,2006)$ and Figueiredo (2019). From a practical point of view, the research examines the audios and interaction transcripts of 11 B1 level learners who attended a course at the University of São Paulo during the second half of 2017. As main results, we observed that the tasks provided complex connective processes, such as noticing, hypothesis testing, scaffolding, which allowed us to advance the hypothesis that these activities promoted significant dialogue and, therefore, the production of languagings that contribute decisively to the construction of knowledge of the foreign language.

Keywords: teaching of Italian as foreign language. Task. linguistic corpus. collaborative dialogue. Interaction.

\section{Introdução}

A experiência que será aqui apresentada nasce de reflexões desenvolvidas em decorrência de minha pesquisa de doutorado realizada entre os anos de 2015 e 2019 na Universidade de São Paulo. Embora naquela ocasião o foco central tenha sido o estudo dos efeitos de técnicas implícitas e explícitas no aparecimento e aprimoramento de competência sociolinguística em aprendizes de italiano, pude perceber com o decorrer do tempo que as tarefas propostas em classe para aquele fim, desenhadas a partir de corpus, pareciam catalisar outros processos facilitadores da aprendizagem de línguas estrangeiras.

Com base nessa impressão inicial, optei por voltar-me novamente aos dados coletados durante a pesquisa de doutorado para realizar uma análise das interações em sala de aula entre os alunos participantes do estudo, dessa vez, 
porém, com vistas a identificar de maneira mais detida quais eram as consequências da utilização de tarefas.

Também me motivou nesse intuito, o fato de ter me dedicado no ano de 2020 a um levantamento do histórico da Linguística de corpus (doravante LC) na Itália e de ter verificado, como se verá mais adiante, uma escassez de investigações centradas na descrição de experiências empíricas que unissem a LC ao Ensino aprendizagem de línguas estrangeiras.

De maneira mais específica, a presente proposta terá como objetivo fornecer resposta à seguinte questão: em que medida o trabalho com tarefas baseadas em corpus pode influenciar a aprendizagem de língua estrangeira?

Do ponto de vista organizacional, este artigo está assim disposto: na primeira seção, será traçado um breve histórico da LC na Itália, enfocando algumas de suas linhas de tendência. Posteriormente, serão enfocados os conceitos de tarefa e de diálogo colaborativo por serem eles de fundamental importância para a interpretação dos dados reunidos ao longo da investigação. Em seguida, serão expostos a metodologia que norteou o estudo e os resultados obtidos. Por fim, será fornecida resposta à pergunta de pesquisa e feitas nas considerações finais.

\section{A LC italiana: momentos fundamentais e linhas de tendência}

A Linguistica dei corpora, como é denominada em italiano, foi introduzida na península itálica em um primeiro momento em universidades do norte do país, mais especificamente na Universidade de Torino. Segundo narrado pela professora Maria Teresa Zagrebelsky (2005), essa inserção ocorreu apenas em torno da década de 1980, quando, motivada por uma conferência do pesquisador britânico John Sinclair, a docente começa a se interessar pela nova vertente de estudos e a investigar grandes conjuntos de textos autênticos por meio de ferramentas informáticas inovadoras para a época. 
Apesar de a década de 1980 poder ser considerada o marco do ingresso da LC enquanto disciplina autônoma em ambiente acadêmico italiano, é preciso recordar que é anterior a contribuição daquele que pode ser tido como o primeiro estudioso italiano a investigar corpus através de processadores informáticos: o padre jesuíta Roberto Busa, responsável pela produção do Index Thomisticus, que constitui a lematização da obra completa de São Tomás de Aquino. A duração do estudo, que levou mais de trinta anos para ser finalizado (de 1949 a 1980), e a quantidade de palavras, cerca de 9 milhões, dão provas claras do imenso fôlego dispensado pelo pesquisador, principalmente, quando levados em conta os limitados recursos computacionais disponíveis à época. A obra final gerou 56 volumes que totalizam mais de 60 mil páginas.

Desde sua entrada no meio universitário italiano, a LC vem obtendo cada vez mais espaço e despertando sempre mais interesse em pesquisadores até então alheios às pesquisas com interface computacional. Contribuindo decisivamente para seu sucesso e popularização, estão softwares que, produzidos por cientistas de diferentes partes do mundo, são muitas vezes obtidos de forma gratuita, o que facilita enormemente o acesso e contribui para um aumento significativo da democratização da investigação científica.

Comparando a LC italiana àquela desenvolvida em outros países, é possível perceber algumas linhas de tendência que dão um contorno bastante peculiar aos estudos produzidos naquele país. Uma dessas singularidades é mencionada por Sabatini (2011), que sustenta o pioneirismo da Itália em desenvolver desde o século XVII dicionários e descrições de fatos da língua construídos com base em corpus:

[...] più e più volte, nel corso storico della nostra lingua, l'accettabilità dell'uso linguistico, nonché il riconoscimento dell'esistenza della lingua stessa e ogni argomentazione anche teorica sui fatti linguistici sono stati derivati dalla costituzione preliminare di un concreto corpus di testi. (SABATINI, 2011, p. 32) 
$\mathrm{Na}$ base dessa argumentação está o fato de as primeiras edições do Vocabolario degli accademici della Crusca $(1612,1623,1691,1729)$ terem sido todas elaboradas a partir da reunião de textos literários clássicos, principalmente os produzidos por escritores florentinos, como Dante, Petrarca e Boccaccio. Sabatini coloca então a Itália como um país que funda a descrição de fenômenos linguísticos sobre vastos conjuntos de textos e, por conseguinte, sobre o uso concreto, tendo, portanto, uma vocação quase natural para os estudos empíricos com corpus.

De acordo com Barbera (2013), uma segunda característica que marca profundamente a LC italiana refere-se à adoção de um tom conciliador em relação à polêmica gerativista. Essa postura é inspirada por linguistas não italianos como Charles Fillmore (1992), que considera que tanto linguistas "de poltrona", aludindo ironicamente aos linguistas gerativistas, quanto os linguistas de corpus precisam uns dos outros, uma vez que, em primeiro lugar, nenhum corpus contém todo e qualquer fenômeno lexical ou gramatical que um estudioso possa querer explorar; e, em segundo, porque todo e qualquer corpus, por menor que seja, ensina fatos que o pesquisador nunca imaginaria encontrar se não fosse por meio da análise de dados reais. Assim, a LC na Itália assume que ambas as disciplinas têm a sua relevância na reflexão sobre o fenômeno linguístico e que, ao invés de estarem em lados opostos, seria desejável que elas se complementassem e que estivessem presentes, ainda que em proporções diferentes, nas pesquisas.

Além dessas características, os pesquisadores italianos têm contribuído para uma redefinição do conceito de corpus. A proposta de Barbera (2015), por exemplo, é a seguinte:

Linguisticamente, inoltre, un corpus è una raccolta di atti di parole, e dai fatti di parole raccolti in un corpus si può risalire ai loro correlati stati di langue, anche se certamente non tutti gli elementi di una langue saranno contenuti in un corpus: è l'uso testimoniato dai corpora, anzi, che fonda la langue, 
anche se i corpora essendo per definizione finiti ne rappresenteranno solo un sottoinsieme. (BARBERA, 2015, p. 119)

Barbera, então, aproxima a Linguística de corpus aos conceitos saussurianos de langue e parole, dizendo que o corpus reúne amostras de parole, ou seja, de uso concreto da língua, e que esses usos são fundamentais para se conhecer a langue, isto é, o código linguístico em si. O linguista, portanto, sustenta uma associação que não é vista frequentemente em outros textos, o que confere certa originalidade à vertente italiana.

No que diz respeito às tendências dos estudos no país, é possível dizer que tem havido grande interesse pelos efeitos que a LC pode gerar na promoção da educação linguística. São exemplos dessa perspectiva Barbera (2015) e Zagrebelsky (2005). Apesar disso, como esclarecem Guidetti, Lenzi e Storchi (2012, on-line), são "più rare, anche se non assenti le testimonianze dirette di un utilizzo effettivo da parte dei docenti”.

Observando mais de perto os estudos da LC relacionados ao ensino de italiano/LE, é possível notar que uma parcela desses trabalhos tem sido realizada com o objetivo de descrever a interlíngua dos aprendizes, identificando possíveis etapas de desenvolvimento (FILIPIN; MARDESIC, 2013; CALABRESE， 2010; CORINO， 2009; ZULOAGA， 2009; COLOMBO, 2009; ONESTI; SQUARTINI, 2009; ALLORA; MARELLO, 2008). Além disso, há também estudos, muito menos numerosos, que descrevem experiências práticas de como introduzir corpora de aprendizes no contexto educacional (MARELLO, 2012). E, finalmente, pesquisas, especialmente de cunho teórico, que procuram sugerir como os recursos disponibilizados pela LC podem ser integrados à atividade docente (CORINO, 2014; GUIDET'TI; LENZI; STORCHI, 2012; LAVIOSA, 1999).

Com relação às propostas propriamente ditas e aos endereçamentos que são dados de como levar corpus para a classe de língua estrangeira, Laviosa 
(1999) afirma que, quando o professor opta por levar um conjunto de textos para que o aluno analise, o ensino passa a dar maior peso àquilo que é de fato recorrente e relevante na língua-alvo. Sendo assim, ao invés de se concentrar em aspectos periféricos, pouco frequentes, como muitas vezes são os tópicos apresentados em livros didáticos, por exemplo, passa-se a priorizar aquilo que aparece com alta frequência e que, portanto, é imprescindível ao aluno.

Concordante ao posicionamento de Laviosa, parto da ótica que enquanto nos livros didáticos a essência das atividades se assentaria em gêneros textuais orais e escritos pré-fabricados e, portanto, menos autênticos, a LC permitiria o contato com textos produzidos por falantes reais, provenientes de diferentes regiões, diferentes realidades sociais e diferentes interesses comunicativos, o que favorecia a introdução de uma multiplicidade de vozes e, em decorrência disso, uma maior compreensão por parte dos alunos daquilo que se constitui como padrão ou como variação na língua-alvo.

Ainda tendo por base as considerações de Laviosa (1999), com a inserção da LC haveria uma otimização do tempo em sala de aula, porém, para que esse fim seja alcançado, ela sugere que o docente avalie sempre seus grupos de alunos e que escolha entre duas maneiras de proceder: se estiver diante de uma sala com aprendizes com um nível de competência comunicativa bastante alto, é interessante que ele leve o conjunto de textos para que os próprios alunos o analisem, partindo de uma perspectiva indutiva por meio da qual serão propostas questões norteadoras que farão com que os aprendizes reflitam e cheguem às regras ou ao léxico mais frequente naquele corpus. Por outro lado, para os falantes menos competentes, Laviosa diz que seria mais produtivo utilizar uma perspectiva híbrida, isto é, ao invés de levar o conjunto de textos para que o aluno analise, o docente faria um filtro e analisaria os dados previamente, planejando sua sequência didática com base nas análises por ele empreendidas. Assim, o professor teria maior 
previsibilidade de suas ações e, ao mesmo tempo, o aprendiz estaria focado em uma tarefa menos complexa do ponto de vista cognitivo.

\section{Interação em classe: da tarefa ao diálogo colaborativo}

Como o título desse trabalho deixa claro, para a construção e exame dessa experiência de ensino, foram fundamentais os conceitos de tarefa e de diálogo colaborativo. Assim sendo, aqui será feita a apresentação de suas definições e principais características.

A noção de tarefa se tornou conhecida em meados dos anos 1980 quando Prabhu desenvolvia na Índia o Programa de Procedimentos (Procedural Syllabus), que, voltado para o ensino de línguas estrangeiras em escolas públicas de nível secundário, foi alicerçado em atividades que solicitavam a atenção dos alunos para o significado, ou seja, para a compreensão e produção de enunciados, em nítida oposição à tendência estruturalista, que privilegiava as formas linguísticas em exercícios de cunho estritamente gramatical.

Em uma de suas primeiras tentativas de definir o termo, Prabhu afirma: "An activity which required learners to arrive at an outcome from given information through some process of thought, and which allowed teachers to control and regulate that process, was regarded as a "task"'.(PRABHU, 1987, p. 24)

Essa primeira elucidação coloca ênfase nos processos cognitivos que são estimulados pelas tarefas, além de expor um dos pré-requisitos fundamentais desse tipo de ensino: a produção de um resultado (outcome). Também deixa claro que durante as tarefas o professor deve ter a possibilidade de "regular", ou seja, intermediar o processo, podendo observar o desempenho dos aprendizes à medida que desenvolvem as etapas da atividade.

Tendo em vista o conceito formulado inicialmente por Prabhu, diversas outras definições surgem ao longo do tempo, como a de Candlin (1987), 
Nunan (1989), Scaramucci (1996), Willis (1996), Ellis (2003), Xavier (2007), entre tantos outros.

Mais recentemente, em 2009, Ellis publica o texto Task-based language teaching: sorting out the misunderstandings, no qual assume o escopo de defender o ensino baseado em tarefas, já que, segundo ele, muitas das críticas feitas à abordagem se devem ao fato de os críticos não perceberem que o TBLT (como é chamado é inglês), na realidade, não constitui uma visão unívoca de ensino, mas se divide em pelo menos três tendências: aquela defendida por Long (1985), a de Skehan (1998) e a do próprio Ellis (2003).

Nesse texto de 2009, Ellis diz que, para ser considerada uma tarefa, a atividade deve satisfazer quatro critérios:

1. The primary focus should be on 'meaning' (by which is meant that learners should be mainly concerned with processing the semantic and pragmatic meaning of utterances).

2. There should be some kind of 'gap' (i.e. a need to convey information, to express an opinion or to infer meaning).

3. There is a clearly defined outcome other than the use of language (i.e. the language serves as the means for achieving the outcome, not as an end in its own right).

4. Learners should largely have to rely on their own resources (linguistic and non-linguistic) in order to complete the activity.

(adaptado de ELLIS, 2009, p. 223)

O ponto 1 permite entrever uma das características sobre as quais primeiro Prabhu apoiou a ideia de tarefa: o fato de o aprendiz precisar estar concentrado em se expressar por meio da língua-alvo, ou seja, em construir enunciados compreensíveis, coerentes e adequados ao objetivo maior da interação. Isso não quer dizer, contudo, que a tarefa não deixe nenhum espaço para a atenção às formas linguísticas, pelo contrário, será durante a interação que vários mecanismos serão postos em funcionamento, o que poderá levar o aprendiz a prestar atenção e a monitorar as estruturas que está utilizando para a formulação de suas ideias. Todavia, esse foco na forma ocorrerá de maneira natural, incidental, sem que uma dada estrutura "tenha que ser" 
necessariamente praticada em virtude de uma solicitação explícita do professor, do livro didático ou do enunciado de uma atividade. A utilização da estrutura emergirá do anseio do aprendiz em se comunicar e, portanto, adquirirá um significado muito maior do que se tivesse sido eliciada propositalmente por meio de um exercício gramatical.

No segundo ponto de sua definição, Ellis chama a atenção para a existência de uma necessidade de "transmitir informações". Em outras palavras, o aluno se vê diante de uma situação na qual precisa se posicionar seja para dar sua opinião, para criar hipóteses sobre um determinado problema, para narrar um acontecimento. Nesse sentido, diferentemente do que ocorre em exercícios de prática estrutural (na grande maioria das vezes pensados como atividades escritas e repetitivas), quando envolvido com tarefas, o aprendiz acaba tendo que se colocar enquanto falante da língua-alvo, o que lhe tira da zona de conforto e, ao mesmo tempo, impõe que ele faça um uso da língua que reflita os atos comumente realizados na vida real, como perguntar, responder, desfazer mal entendidos, argumentar, brincar, etc.

Todos esses pontos estão conectados à presença do ponto 3: uma instrução na tarefa que prevê um "resultado claramente definido". Vale dizer então que para que seja considerada uma tarefa não basta que o aprendiz se engaje em uma comunicação semelhante àquelas que temos na vida real, mas sim que essa interação possua um objetivo outro, como a definição de um roteiro de viagem em grupo, a solução de um enigma, a resolução de um problema prático, a produção e/ou execução de um jogo, a eleição de um livro ou música preferida e assim sucessivamente. Consequentemente, para além da finalidade comunicativa, a língua-alvo deve ser empregada para se atingir um outcome que não necessariamente deverá ser linguístico.

Finalmente, o ponto 4 coloca em evidência a dependência dos aprendizes com relação a seus próprios recursos linguísticos e não linguísticos 
para atingirem o escopo da atividade. Com isso, enfatiza-se que o aprendiz precisará colocar em atividade seu repertório na língua-alvo, ativando seu conhecimento quanto a elementos lexicais, morfossintáticos, pragmáticos, prosódicos, fonéticos, etc.

Em sala de aula de língua estrangeira, onde diferentes aprendizes interagirão para realizar tarefas, será justamente esse esforço comum em colocar em prática a própria competência comunicativa que abrirá caminho ao diálogo colaborativo, na medida em que um determinado aprendiz, reconhecendo se encontrar na mesma situação de seu interlocutor (também ele aprendiz), provavelmente se sentirá mais à vontade tanto para demonstrar suas dúvidas e incertezas quanto para contribuir para a construção dos enunciados dos companheiros.

Concentrando-me a partir desse momento nesse segundo conceito chave, cabe relembrar que a ideia de diálogo colaborativo nasce no interior da teoria sociocultural vygotskyana, segundo a qual os seres humanos

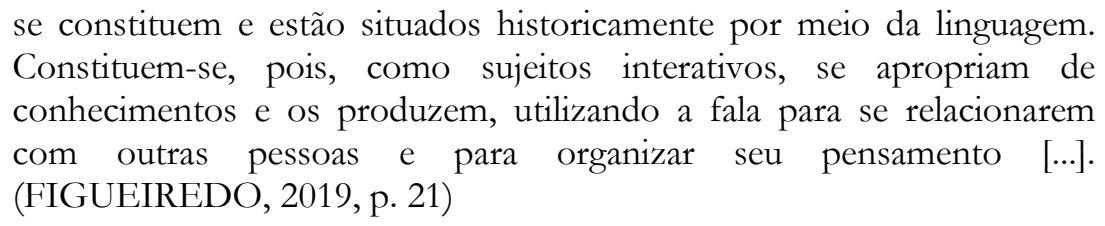

Por esse ponto de vista, a interação assume um papel central no desenvolvimento dos indivíduos, na medida em que o diálogo tem o potencial de permitir que os aprendizes aprendam a língua enquanto a usam para se comunicar e se relacionar com o professor ou com falantes mais competentes. Portanto, o diálogo, ao mesmo tempo em que faz com que o aluno aprimore as relações interpessoais, estimula a consolidação da aprendizagem por meio do uso/reflexão na língua-alvo.

Avançando ainda mais as discussões sobre esse ponto, Swain tem se detido desde os anos 1990 sobre a relevância de se estimularem situações em 


\section{O estímulo ao diálogo colaborativo a partir de tarefas baseadas em corpus: uma experiência no ensino de italiano/LE Graziele Frangiotti}

classe em que o aprendiz se veja imerso no uso significativo da linguagem. Para ela, apenas receber insumo, ou seja, ler e ouvir textos na língua-alvo, não é suficiente para assegurar o desenvolvimento da competência comunicativa, logo é condição essencial para a aprendizagem a produção linguística (output) ou, como mais recentemente denominado por ela, o languaging (traduzido por Figueiredo [2019] como lingualizaçãa).

Em textos mais recentes, Swain tem sustentado a posição de que o languaging é uma ferramenta cognitiva que "se refere a uma ação - um processo dinâmico, interminável - de uso da língua para produzir significado” (2006, p. 96). Mais precisamente, Swain acredita que essa ferramenta difere da simples transmissão de mensagens por meio da fala e/ou da escrita, pois abarca uma tentativa por parte do aprendiz de entender, resolver problemas na língua-alvo, o que consentiria um aprimoramento da competência comunicativa. Para ela,

In fact, it is precisely when language is used to mediate problem solutions, whether the problem is about which word to use, or how best to structure a sentence so it means what you want it to mean, or how to explain the results of an experiment, or how to make sense of the action of another, or ... that languaging occurs. (SWAIN, 2006, p. 96)

$\mathrm{Na}$ base do languaging está a convicção de que externar uma reflexão sobre/na língua-alvo opera uma verdadeira transformação mental do aluno, pois não requer apenas o puro e simples acesso à memória, mas sim a ativação de toda uma gama de pensamentos que deverão ser traduzidos em forma de discurso.

Segundo nossa leitura, o diálogo colaborativo e o languaging seriam capazes de propiciar a ocorrência de outros processos particularmente relevantes para a aprendizagem, como o noticing e suas variantes - o noticing the bole e o noticing the gap-, além do scaffolding (o andaime) e do teste de hipótese. 
O noticing é um conceito desenvolvido inicialmente por Schmidt e Frota (1986) que foi posteriormente retomado por Schmidt (1990, 1993, 1994), equivalendo ao momento no qual o aprendiz nota conscientemente algo novo na língua aprendida. Graças a essa etapa, o aluno procuraria compreender e processar cognitivamente o aspecto percebido (intake), buscando integrá-lo progressivamente à sua produção.

O noticing the gap diz respeito à ideia de que o aprendiz, em interação com professores ou com falantes mais competentes que ele, seria capaz de identificar que a forma linguística utilizada por ele não corresponde à forma empregada pelo falante mais experiente, o que o levaria posteriormente a procurar soluções mais congruentes com a língua-alvo.

Já o noticing the hole se referiria à capacidade de o aprendiz perceber que não consegue formular aquilo que gostaria, seja porque não conhece um determinado elemento lexical seja porque não se lembra ou não sabe como certa estrutura é construída (SWAIN, 1995).

As interações entre aprendizes ou entre o aprendiz e um falante mais competente teria também a função de abrir espaço para o scaffolding, que se refere, nas palavras de Figueiredo (2019):

a técnicas instrucionais usadas por professores, ou por parceiros mais experientes, como apoio temporário para que os aprendizes obtenham progressivamente compreensão sobre como realizar determinada tarefa e possam, posteriormente, realizá-la de forma independente. (p. 52)

Finalmente, segundo Swain (2005, p. 476), o teste de hipótese é "from the learner's perspective, a 'trial run' reflecting their hypothesis of how to say (or write) their intent", ou seja, um conjunto de tentativas feitas pelo aprendiz no sentido de construir o enunciado para comunicar aquilo que deseja.

Vistos até aqui os principais conceitos teóricos que respaldam este estudo, passarei a seguir à descrição metodológica. 


\section{A experiência com tarefas baseadas em corpus}

O curso focalizado - intitulado Italiano in contesto - foi estruturado em cinco unidades de trabalho, perfazendo um total de 20 horas de atividade em sala. Foi oferecido no âmbito do Serviço de Cultura e Extensão da Universidade de São Paulo, na modalidade presencial entre os meses de outubro e novembro de 2017.

Para sua realização, contamos com a participação de 11 alunos, todos com nível não inferior ao B1, conhecimento verificado a partir de um teste de seleção inicial ao qual todos foram submetidos antes do início das aulas.

As sequências didáticas visavam ao desenvolvimento de competência sociolinguística. Portanto, foram formuladas de modo a abranger fenômenos linguísticos representativos das variedades orais e escritas ao longo do contínuo da formalidade-informalidade. Desse modo, eram estudados gêneros textuais autênticos e estimulada, por meio da leitura desses textos e de questionários de compreensão textual, a reflexão acerca do contexto de produção, bem como o tipo de relação estabelecida entre os interlocutores e suas intenções interacionais.

No que diz respeito ao tratamento das variáveis linguísticas, a perspectiva adotada foi de tipo explícito-indutiva. Na prática, isso significa que o trabalho com traços sociolinguisticamente marcados se deu através da apresentação de tabelas-síntese, nas quais eram reportados dados gerados a partir da análise de corpus.

Essas tabelas, como se vê pelo exemplo abaixo, traziam a distribuição de variantes linguísticas em quatro gêneros textuais marcados em diafasia e diamesia. A partir delas, era proposta a realização de tarefas aos aprendizes, de modo que eles deviam discutir e chegar a um consenso único no interior de duplas ou de trios acerca dos possíveis motivos que justificavam essas diferenças na frequência de uso. 
O estímulo ao diálogo colaborativo a partir de tarefas baseadas em corpus: uma experiência no ensino de italiano/LE

Graziele Frangiotti

Figura 1: Exemplo de tabela-síntese levada à sala de aula

\begin{tabular}{|c|c|c|c|c|c|}
\hline Gênero & $\begin{array}{c}\text { Form } \\
\text { as }\end{array}$ & $\begin{array}{c}\text { Conj. } \\
\text { Adversativa } \\
\text { s }\end{array}$ & $\begin{array}{l}\text { Conj. } \\
\text { causais }\end{array}$ & $\begin{array}{c}\text { Conj. } \\
\text { concessivas }\end{array}$ & $\begin{array}{c}\text { Conj. } \\
\text { conclusivas }\end{array}$ \\
\hline E-mail & 26 & $\begin{array}{l}\text { ma (94) } \\
\text { tuttavia (12) } \\
\text { però (11) } \\
\text { ciononostan } \\
\text { te (5) } \\
\text { bensì (2) } \\
\text { piuttosto (2) } \\
\text { eppure (1) }\end{array}$ & $\begin{array}{c}\text { poiché (32) } \\
\text { perché (28) } \\
\text { in quanto (24) } \\
\text { dal momento che } \\
(11) \\
\text { dato che (7) } \\
\text { siccome (2) } \\
\text { visto che (2) } \\
\text { giacché (1) }\end{array}$ & $\begin{array}{c}\text { nonostante } \\
\quad(19) \\
\text { pur (8) } \\
\text { anche se (6) } \\
\text { sebbene (5) } \\
\text { seppur (2) } \\
\text { malgrado (1) }\end{array}$ & $\begin{array}{c}\text { quindi (25) } \\
\text { pertanto(13) } \\
\text { dunque (9) } \\
\text { così (6) } \\
\text { per cui (5) }\end{array}$ \\
\hline $\begin{array}{l}\text { Plantão } \\
\text { docente }\end{array}$ & 13 & $\begin{array}{c}\text { però (34) } \\
\text { ma (8) } \\
\text { invece (3) } \\
\text { mentre (1) } \\
\text { piuttosto } \\
\text { che (1) }\end{array}$ & $\begin{array}{l}\text { perché (59) } \\
\text { visto che (2) } \\
\text { dato che (1) } \\
\text { siccome (1) }\end{array}$ & anche se (3) & $\begin{array}{l}\text { quindi (12) } \\
\text { perciò (1) } \\
\text { per cui (1) }\end{array}$ \\
\hline Entrevista & 13 & $\begin{array}{l}\text { però (96) } \\
\text { ma (19) } \\
\text { invece (14) } \\
\text { mentre (9) } \\
\text { anzi (4) } \\
\text { piuttosto } \\
\text { che (3) }\end{array}$ & $\begin{array}{l}\text { perché (111) } \\
\text { siccome (6) } \\
\text { per il fatto che } \\
\text { (1) }\end{array}$ & anche se (14) & $\begin{array}{c}\text { quindi (171) } \\
\text { perciò (3) } \\
\text { allora (2) }\end{array}$ \\
\hline $\begin{array}{l}\text { Mensagem } \\
\text { de texto }\end{array}$ & 14 & $\begin{array}{l}\text { ma }(77) \\
\text { però }(27) \\
\text { anzi }(3) \\
\text { invece }(3)\end{array}$ & $\begin{array}{l}\text { perché (53) } \\
\text { visto che (5) } \\
\text { siccome (1) }\end{array}$ & $\begin{array}{c}\text { anche se (9) } \\
\text { nonostante } \\
(1) \\
\operatorname{pur}(1)\end{array}$ & $\begin{array}{l}\text { quindi (34) } \\
\text { così (6) } \\
\text { perciò (2) } \\
\text { allora (2) }\end{array}$ \\
\hline
\end{tabular}

Com a tabela, se procurava demonstrar que as formas linguísticas, mesmo quando desempenham a mesma função semântica, podem ser avaliadas pelos usuários da língua como mais ligadas a registros formais que a informais, sendo mais utilizadas em certos contextos que em outros. Para encaminhar esse debate, as duplas ou trios eram chamados a responder às seguintes questões: 
1. Para vocês, qual pode ser a explicação para que o número de conjunções usadas nos e-mails seja praticamente o dobro daquelas usadas nos outros gêneros?

2. Considerando ainda os resultados da pesquisa, quais são as conjunções que parecem distinguir os e-mails a professores?

3. Quais são as consequências dessa variação no uso das conjunções para um aprendiz de língua italiana? Pode ser útil conhecê-la? Por quê?

A partir dessas perguntas, era esperado que os alunos percebessem que a diferença na quantidade de formas de conjunções pode estar relacionada ao grau de formalidade e ao canal usado na comunicação, chegando, assim, à conclusão de que textos escritos formais tendem a apresentar maior variedade de formas, enquanto textos escritos informais e orais tendem a ter menor variabilidade.

Com a segunda pergunta, em especial, os alunos eram convidados a voltarem ao quadro para identificar que as conjunções mais usadas nos e-mails foram: as adversativas ma e tuttavia; as causais poiché e perché; as concessivas, nonostante, pur e anche se, e as conclusivas quindi, pertanto e dunque.

$\mathrm{Na}$ terceira pergunta, era solicitado somente que os aprendizes dessem sua opinião sobre a utilidade de saberem da existência dessa variação para eliciar seu posicionamento sobre a importância de se tratar esse tipo de aspecto em cursos de língua estrangeira.

Como se vê, na construção dessa experiência, a opção feita privilegiou a técnica híbrida, como sugerido por Laviosa (1999), segundo a qual, em caso de alunos menos experientes, deve ser feito um filtro prévio dos dados provenientes de corpus, levando os alunos a trabalharem com um número menor e menos complexo de informações.

Além disso, também foi adotada a visão de tarefa como definido por Ellis (2009), visto que o foco das questões inseridas após as tabelas era a discussão em pares e a construção de significado, ainda que a reflexão se desse motivada por dados metalinguísticos. Os alunos também tinham um objetivo 
claro (outcome): deviam entrar em consenso sobre as causas da variação de distribuição para expô-las posteriormente ao grupo. Finalmente, tinham que contar com os próprios recursos linguísticos e não-linguísticos para executar a atividade.

É importante esclarecer que esse procedimento de apresentação foi respeitado em todos os encontros e que não houve nenhum tipo de explicação sobre a distribuição dos fenômenos linguísticos antes que os aprendizes refletissem sobre as tabelas-síntese e as questões propostas a partir delas.

\section{As tarefas e os processos colaborativos suscitados}

Por meio da observação da participação dos alunos durante os encontros, foi possível constatar em várias ocasiões uma alteração significativa no tom de voz e na velocidade de fala dos alunos quando expunham seus argumentos, o que foi interpretado como um sinal de certa excitação e, por conseguinte, de um aumento no grau de envolvimento e do foco no significado em detrimento do foco excessivo na forma, indícios positivos do êxito das tarefas propostas.

Esse aspecto pode ser visualizado no trecho a seguir, no qual estão assinalados em maiúsculo os segmentos textuais enfatizados pelas duas alunas, cujos nomes são fictícios:

\footnotetext{
Sylvia maperme la grande non so... è che qua TUTTI $i$ pronomi appariscono

Rafaella si

Sylvia quello è il dato fondamentale qui perché nel ricevimento TUTTI $i$ pronomi appariscono quando negli altri no c'è una variazione se dove apparisce nelle interviste non apparisce nella mail e nell'Whatsapp non apparisce neanche dove neanche quale

Rafaella ma sai anche se noi in questa situazione del ricevimento abbiamo TUTTI i pronomi non si può indicare una TENDENZA grande perché quale si usa due volte dove una volta vedi non è una TENDENZA

Sylvia ma ma se tu vedi qui ci sono il numero totale centosessantuno e nel ricevimento solo NOV ANTA è quasi la metà ma nella metà c'è una variazione MOLTO
} 
O estímulo ao diálogo colaborativo a partir de tarefas baseadas em corpus: uma experiência no ensino de italiano/LE

Graziele Frangiotti

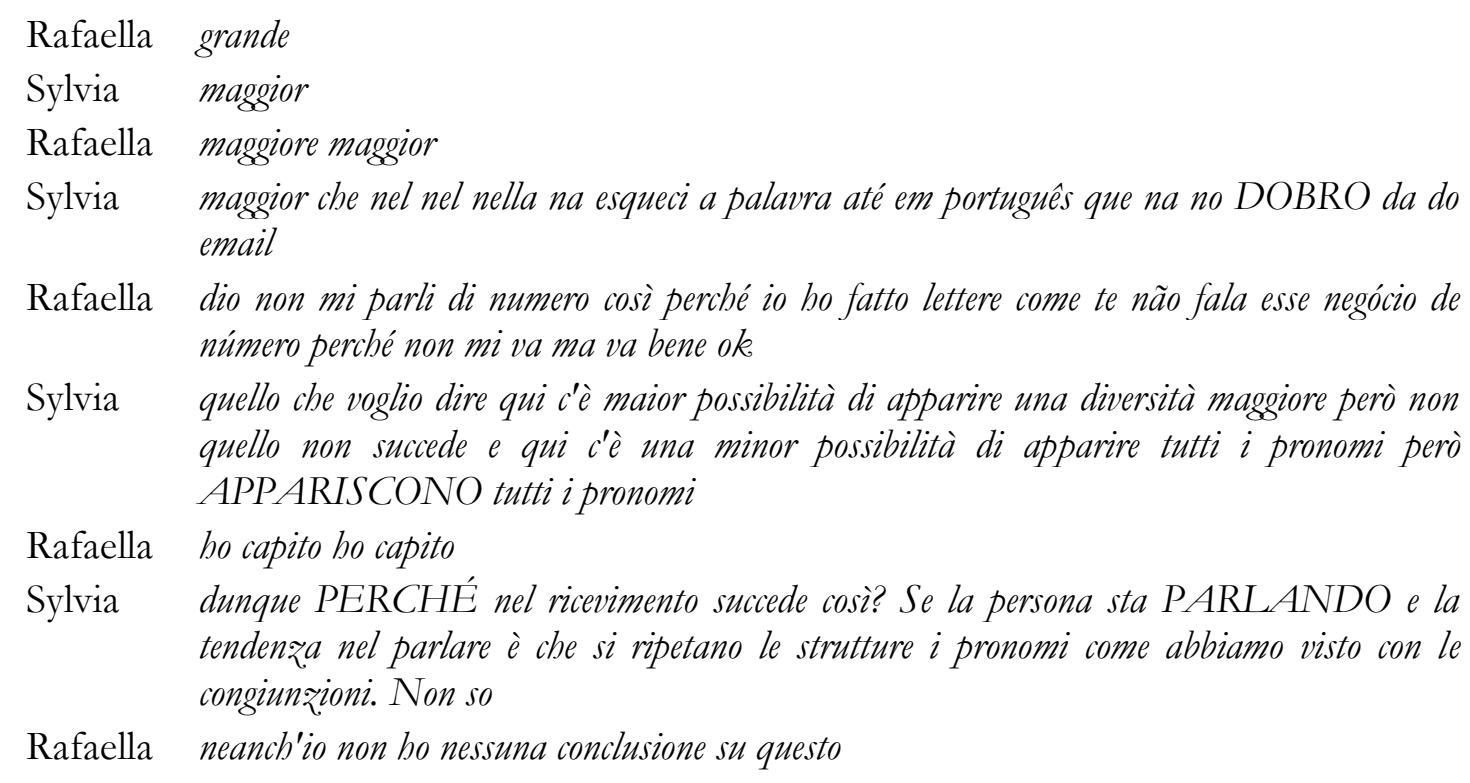

Nesse momento da interação, é discutida a distribuição das ocorrências de pronomes relativos (cui, quale, che e dove) nos quatro gêneros textuais sob exame. O impasse das alunas reside no fato de a tabela com esses dados revelar que há grande diversidade de formas pronominais nos plantões com professores (gênero oral formal), o que contraria, na visão de Sylvia, a tendência natural de, na fala, se repetirem sempre as mesmas palavras.

Nesse diálogo, ocorre o aumento no tom de voz das alunas que estão interagindo, principalmente a partir do quarto turno de fala, no qual a aluna Rafaella refuta a ideia expressa por Sylvia, procurando argumentar que não era possível falar de uma tendência em se utilizarem mais formas, uma vez que os números encontrados eram baixos.

A partir desse ponto, há um esforço por parte de Sylvia em contraargumentar, descrevendo melhor o seu ponto de vista e, inclusive, lançando mão dos números presentes na tabela para fortalecer seu raciocínio. Sylvia deixa claro, então, seu anseio em reiterar sua perspectiva e em convencer Rafaella de que o que ela estava dizendo fazia sentido.

$\mathrm{Na}$ tentativa de reconstruir sua reflexão, Sylvia, em seu terceiro turno, parece constatar uma lacuna em seu repertório linguístico, o que lhe faz 
hesitar, dando a oportunidade para que Rafaella procure ajudá-la através do oferecimento da alternativa grande, não aceita por Sylvia, que opta então por testar maggior, uso que é ratificado por Rafaella.

Ocorre, aqui, um exemplo de diálogo colaborativo que dá lugar a pelo menos cinco processos relacionados à aprendizagem: em primeiro lugar, o languaging (Swain, 2006), visto que Sylvia reflete sobre a língua-alvo valendo-se da língua-alvo e traduzindo seu pensamento em discurso. Há também uma ocorrência de noticing the bole (SWAIN, 1995), na medida em que Sylvia interrompe o fluxo conversacional por perceber não ser capaz de encontrar naquele momento uma maneira de expressar adequadamente sua ideia; em seguida, a colega, em uma nítida postura colaborativa (SWAIN 1995, 2000, 2005, 2006), oferece-lhe uma alternativa; posteriormente, há o teste de hipótese por parte de Sylvia (SWAIN, 2005) e, enfim, a confirmação colaborativa da pertinência do uso de maggior por Rafaella.

Na sequência, há um novo noticing the hole, quando Sylvia não consegue encontrar uma alternativa para o termo "dobro", o que lhe faz passar à língua materna para se fazer compreender. Rafaella responde em italiano, mas traduz em seguida seu enunciado para o português, como se tentasse convergir sua produção na direção de sua interlocutora, o que reforça ainda mais sua atitude colaborativa.

Esse turno é finalizado com Rafaella dizendo que estava tudo bem, dando a entender que já havia entendido a perspectiva de Sylvia e que, sendo assim, podiam passar ao próximo tópico da tarefa. Sylvia, no entanto, reafirmando o seu interesse em convencer a colega, retoma a discussão e reformula seu argumento, sintetizando-o, dessa vez, sem rupturas no fluxo conversacional.

Rafaella, aparentemente numa tentativa de encerrar a discussão, diz ter entendido. Sylvia, então, em um tom que demonstra certa "indignação" em 
relação aos números presentes na tabela, coloca um questionamento final, que tem a função de resumir sua dúvida, ao mesmo tempo em que reitera toda sua argumentação. Rafaella diz não poder dar uma resposta à questão e, ao fazêlo, dá indícios de ter aceitado a exposição da amiga.

Fica evidente que as alunas interagem ativamente criando uma atmosfera de uso autêntico e significativo da língua-alvo, na qual a discussão metalinguística gera indagações, conflitos e argumentações muito próximas àquelas encontradas na vida diária, favorecendo não apenas $\mathrm{O}$ desenvolvimento da competência linguística propriamente dita, mas também a discursiva, relacionada à capacidade de produzir, entre outras coisas, textos persuasivos coerentes.

No exemplo que segue, retirado de uma interação durante o quinto encontro, a dupla se concentra na análise das frequências de ocorrência de superlativos e diminutivos em textos formais e informais:

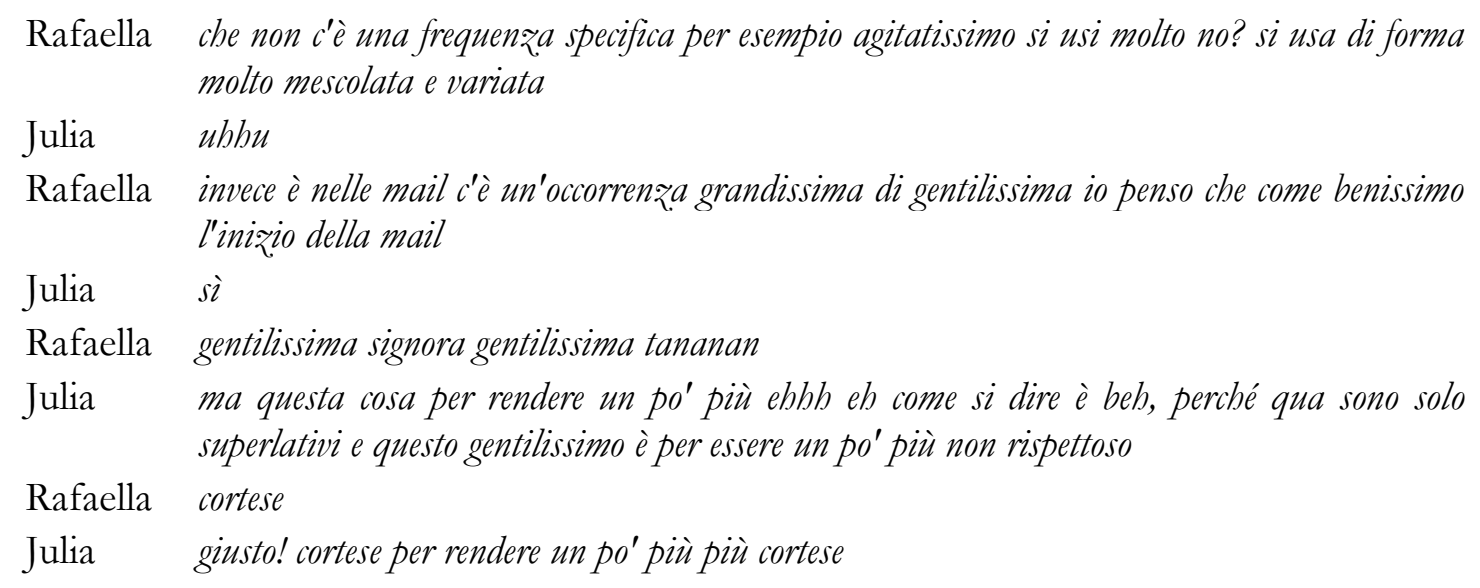

No primeiro turno, uma das aprendizes, Rafaella, começa a levantar hipóteses de interpretação dos dados: ela diz que não é possível detectar quais termos seriam mais propensos a serem usados no superlativo. Segundo afirma, não é possível estabelecer, por exemplo, que apenas o adjetivo agitato é empregado no superlativo, uma vez que as tabelas revelavam que diversas outras formas poderiam ser candidatas à alteração. Além disso, no seu 
segundo turno, ela supõe que a alta frequência de gentilissima nos e-mails estaria relacionada à sua função vocativa, enquanto fórmula de abertura nesse gênero textual.

Julia, que até então somente concordava com as ideias da colega, toma o turno e procura complementar as hipóteses da colega. A seu ver, gentilissimo desempenha uma função específica nos e-mails, conferindo-lhe maior cortesia. No entanto, no momento de enunciar a parte final, ela hesita, percebendo não se recordar/não conhecer um termo capaz de expressar com precisão a sua ideia, numa ocorrência de noticing the hole. Posteriormente, ela solicita a ajuda de sua interlocutora, o que fica evidente quando diz "eh come si dire è?". Como não consegue achar um termo adequado, ela procura reconstruir o enunciado e, enfim, faz um teste com o termo rispettoso, que, porém, não a satisfaz. Rafaella então, em uma atitude colaborativa, oferece a alternativa: cortese, que, pelo tom exclamativo de Julia, constituía exatamente o termo que estava à procura.

O excerto abaixo também parece ratificar o papel das tarefas baseadas em corpus em impulsionar o diálogo colaborativo e demais processos cognitivos:

Elena poiché non appare mai negli altri solo nella mail perché appare in tutti ma quelli che sono più informale li mettono di più tranne Whatsapp che c'è solo una volta ehbh

Coralina perché è più usato nel ricevimento e nel Whatsapp

Elena e visto che è uguale penso che non viene usato da italiani visto che sai che non avevo mai sentito visto che pensavo che non era italiano pensavo che era un modo brasiliano

Coralina visto che

Elena sai che non ho mai usato perché pensavo che non era italiano

Aqui, as aprendizes falam da frequência e dos tipos de conjunções ou locuções conjuntivas presentes nos quatro gêneros. Elas constroem hipóteses interpretativas, como aquela identificada no primeiro turno, no qual associam a maior presença da conjunção perché aos gêneros textuais mais informais. 
Em seguida, elas passam a considerações quanto à locução visto che, inicialmente não identificada por Elena como usada por italianos. Logo na sequência, parece ocorrer o que Schmidt e Frota denominam noticing (1986), isto é, Elena parece se dar conta conscientemente da existência desse elemento, que, até então, segundo ela, era visto como uma característica presente apenas na interlíngua de aprendizes brasileiros. Imediatamente depois, no último turno, há um noticing the gap, quando Elena nota a distância da sua produção em relação à produção de falantes italianos.

Como último exemplo, há um trecho do diálogo entre os estudantes Marta e Marco, no qual falam das variáveis deslocamento à esquerda e à direita. No início da interação, eles se concentram na função desse recurso linguístico para, em seguida, passarem à leitura e interpretação da tabelasíntese:

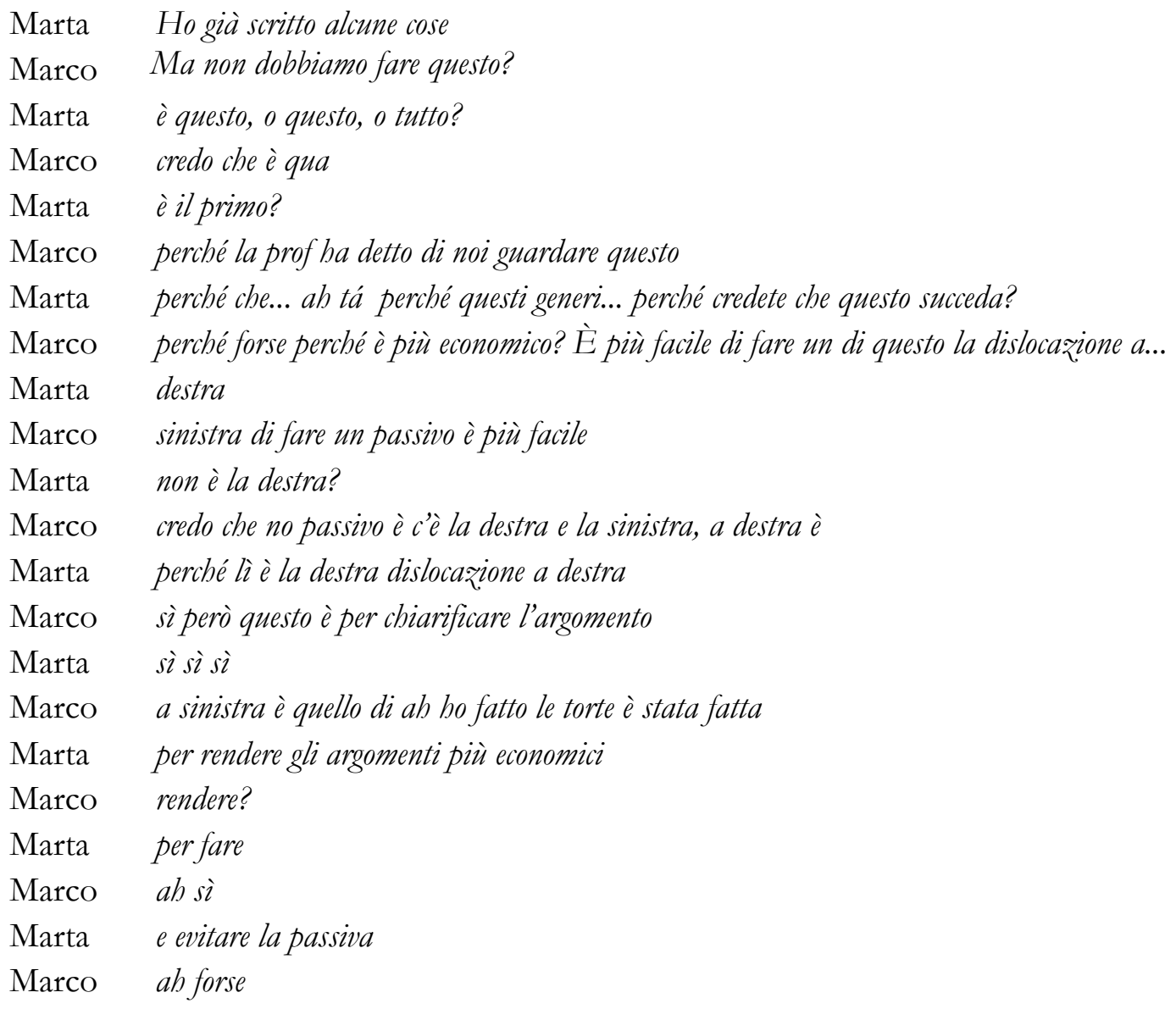


O estímulo ao diálogo colaborativo a partir de tarefas baseadas em corpus: uma experiência no ensino de italiano/LE Graziele Frangiotti

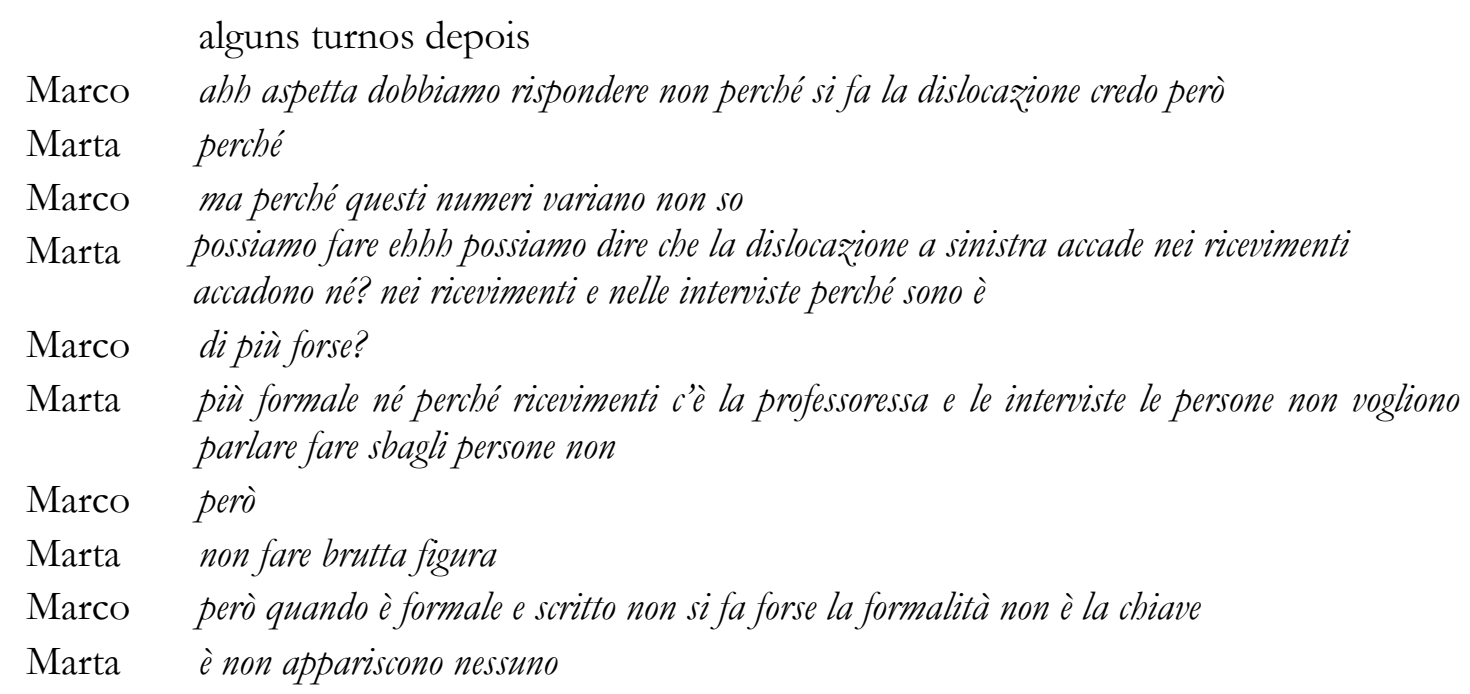

Já nos primeiros turnos da conversa, ocorre um scaffolding oferecido por Marco, que esclarece à Marta o que deve ser feito na atividade. Ele introduz o apoio à colega a partir de um questionamento: "Ma non dobbiamo fare questo?". Esse tipo de estratégia é denominado por Reiser (2004) scaffolding problematizing (problematizador), e ocorre quando um parceiro questiona o outro com o intuito de lhe fazer pensar em como resolver a tarefa.

Graças ao andaime oferecido por Marco, Marta então compreende o que deve fazer, ela o manifesta linguisticamente quando, no quarto turno de fala, passa ao português e diz [...] ah tá, concordando com as observações e argumentos fornecidos pelo colega. Inicia-se assim a realização da tarefa propriamente dita. Marco lança mão de sua primeira hipótese, alegando que o deslocamento à esquerda seria a forma preferida pelos falantes pelo fato de ser "econômico", ou seja, mais fácil de ser produzido se comparado a uma oração na voz passiva. Marta o interrompe para também oferecer um scaffolding. Em seu caso, ela esclarece que aquele não é um deslocamento à esquerda, como sustenta Marco, mas sim um deslocamento à direita. Vê-se nos próximos oito turnos uma negociação do significado que culmina no noticing the bole e no subsequente pedido de esclarecimento por parte de Marco acerca da palavra 
"rendere". Marta, colaborativamente, oferece-lhe um scaffolding estruturante, indicando o verbo fare como sinônimo de rendere.

Após alguns turnos conversacionais, Marco oferece novamente um andaime à colega, colocando em evidência que a tarefa não prevê apenas a reflexão sobre a função dos deslocamentos, mas sim que é necessário que se pense nas diferentes distribuições dos fenômenos nos quatro gêneros. Marta coloca sua primeira hipótese interpretativa, afirmando que a maior presença de deslocamentos nos plantões docentes e nas entrevistas se devia à maior formalidade desses gêneros. Marco rejeita essa suposição, argumentando que os dados da tabela contradizem o raciocínio sustentado por ela. Segundo ele, a chave da variação não é o grau de formalidade. Marta então concorda com o ponto levantado pelo colega, na medida em que, voltando-se à tabela, constata que, de fato, nos e-mails, também eles representativos do polo formal, não ocorre nenhum deslocamento.

Embora a discussão travada por Marco e Marta não os conduza ao real motivo da variação, toda a construção colaborativa do discurso e os vários exemplos de andaimes oferecidos por ambos os participantes da interação dão provas da eficácia da tarefa como promotora do engajamento dos alunos e da formulação de raciocínios e argumentos bastante complexos, o que favorece o desenvolvimento linguístico como um todo. É importante salientar, no entanto, que, após essas discussões em pares, os alunos compartilhavam seus posicionamentos e dúvidas, justamente para que tivessem a oportunidade de resolver possíveis mal-entendidos ou incompreensões.

\section{Considerações finais}

Como elucidado na introdução a esse artigo, a presente proposta visava responder à seguinte questão: em que medida o trabalho com tarefas baseadas em corpus pode influenciar a aprendizagem de língua estrangeira? Para atingir 
esse propósito, a investigação foi estruturada a partir da análise das interações estabelecidas entre 11 aprendizes de italiano de nível B1 durante a realização de tarefas em um curso explícito cujo foco central era a promoção de sensibilidade à variação linguística.

Partindo de uma perspectiva sociocultural e alicerçada sobre os estudos de Vygotsky, Swain e Figueiredo, a hipótese inicial era a de que as interações poderiam gerar efeitos sobre o desenvolvimento da competência comunicativa.

Com a análise empreendida nas gravações de áudio e transcrições das falas desses alunos, foi possível verificar o surgimento de processos que, segundo a literatura retomada, estão diretamente associados à aprendizagem de línguas.

Efetivamente, enquanto realizavam as tarefas projetadas pela professora, os alunos se engajaram ativamente em diálogos que ocasionaram diversas práticas colaborativas. Como foi possível testemunhar, ao longo dessas interações, os aprendizes ofereceram inúmeros scaffoldings, na medida em que procuraram ajudar seus colegas a compreender melhor as etapas de execução da tarefa, assim como os auxiliaram na formulação de enunciados mais congruentes com a língua-alvo.

Também foi detectada a recorrência de languagings, ou seja, a reflexão sobre diferentes tipos de aspectos da língua-alvo através de enunciados formulados na própria língua-alvo, além de noticings, noticings the bole, noticings the gap, que, como já explicitado, dizem respeito a processos de tomada de consciência acerca da existência de um dado aspecto na língua estrangeira e à sua possível transformação em intake. Por fim, foram bastante frequentes os testes de hipótese em que os aprendizes, não seguros de suas escolhas lexicais e gramaticais, fazem tentativas no anseio de se comunicarem. 
Como visto até aqui, as tarefas baseadas em corpus se mostraram relevantes e produtivas, pois promoveram a interação significativa, ou seja, aquela da qual o aprendiz participa verdadeiramente, constituindo-se como um falante que argumenta, refuta, contribui, reflete, acrescenta e constrói enunciados na língua-alvo. Indo além, esse engajamento desencadeia processos cognitivos complexos que estimulam o foco na forma, assim como favorecem a consolidação de vocabulário e de estruturas gramaticais ao mesmo tempo em que catalisam a construção colaborativa do conhecimento em língua estrangeira.

\section{Referências}

ALLORA, A.; MARELLO, C. L'aggettivazione in scritti di apprendenti l'italiano come L2. In: BERNINI, L.; SPREAFICO, A. V. (a cura di). Competenze lessicali e discorsive nell'acquisizione di lingue seconde. Perugia: Guerra, 2008, 17-36.

BARBERA, M. Per uma soluzione teorica e storica dei rapporti tra grammatica generativa e linguistica dei corpora. In: - Molti occhi sono meglio di uno solo: saggi di linguistica generale 2008-12, 2013, 27-45. Disponível em: <https://www.bmanuel.org>. Acesso em 20 dez. 2020.

Quanto più la relazione è bella: saggi di storia della lingua italiana 1999-2014. Torino, 2015. Disponível em: <https://www.bmanuel.org>. Acesso em: 20 dez. 2020.

BUSA, R. SJ. Index Thomisticus. Edição online de Eduardo Bernot e Enrique Alarcón, 2005. Disponível em: <http://www.corpusthomisticum.org/it/index.age $>$. Acesso em: 20 dez. 2020.

CALABRESE, R. Analisi dell'interlingua e sistemi di annotazione: implicazioni teoriche ed indagini empiriche. Testi e linguaggi., v. 4, 2010, 151 158.

Disponível: <http://elea.unisa.it:8080/jspui/bitstream/10556/685/1/Calabrese $\% 2 C \% 20$ R.\%20Analisi $\% 20$ dell $\% 27$ interlingua $\% 20 \mathrm{e} \% 20$ sistemi $\% 20 \mathrm{di} \% 20$ annotazione. 
$\% 20$ Implicazioni $\% 20$ teoriche $\% 20$ ed $\% 20$ indagini $\% 20$ empiriche.pdf $>$. Acesso em 20 dez. 2020.

CANDLIN, C. N. Towards task-based language learning. In: CANDLIN, C. N.; MURPHY, D. Language learning tasks. Lancaster/Englewood Chiffs, NJ: Prentice-Hall International, 1987.

COLOMBO, O. L'apprendimento dell'alterazione in italiano L2 in produzioni scritte di francofoni. In: CORINO, E.; MARELLO, C. (a cura di) VALICO. Studi di linguistica e didattica. Perugia: Guerra, 2009, 111-135.

CORINO, E. Varietà di apprendimento e subordinazione. Studi a cavallo tra VALICO e VINCA. In: CORINO, E.; MARELLO, C. (a cura di). VALICO: studi di linguistica e didattica. Perugia: Guerra, 2009, 71-95.

Didattica delle lingue corpus-based. Educarione Linguistica. Language Education, v. 3, n. 2, 2014, 231-257.

ELLIS, R. Task-based language learning and teaching. Oxford: OUP, 2003.

Task-based language teaching: sorting out the misunderstandings. International Journal of Applied Linguistics. v. 19, n. 3, 2009, 221-246.

FIGUEIREDO, F. J. Q. Vygostsky: a interação no ensino/aprendizagem de línguas. São Paulo: Parábola, 2019.

FILLMORE, C. J. Corpus linguistics or Computer-aided armchair linguistics. In: SVARTVIK (ed.), 1992, 35-60.

FILIPIN, N.; MARDESIC, S. Analisi dell'interlingua nell'apprendente dell'italiano a livello universitario. Sraz LVII, 201-219, 2013. Disponível em: <https://www.academia.edu/10338988/Analisi_dell_interlingua_nell_appren dimento_dell_italiano_a_livello_universitario>. Acesso em: 20 dez. 2020.

GUIDETTI, M.; LENZI, G.; STORCHI, S. Potenzialità e limiti dell'uso dei corpora linguistici per la didattica dell'italiano LS. Supplemento alla rivista EL.LE, 2012. Disponível em: <https://www.itals.it/potenzialit $\%$ C3\%A0-e-limitidell $\% \mathrm{E} 2 \% 80 \% 99$ uso-dei-corpora-linguistici-la-didatticadell $\%$ E2\%80\%99italiano-ls>. Acesso em: 20 dez 2020. 
LAVIOSA, S. Come studiare e insegnare l'italiano attraverso i corpora. Italica, v. $76, \quad$ n. 4, 1999, 443-453. Disponível em: https://www.jstor.org/stable/480250. Acesso em: 20 dez. 2020.

LONG, M. A role for instruction in second language acquisition: task-based language teaching. In: HYLTENSTAM, K.; PIENEMANN, M. (eds.), Modelling and assessing second language acquisition. Clevedon: Multilingual Matters, 1985.

MARELLO, C. Corpora di apprendenti: come usarli nella didattica dell'italiano in Svizzera. In: DI PRETORO, R. Lingua e letteratura italiana 150 anni dopo l'Unità. Meidenbauer: Monaco. 2012, 299-315.

NUNAN, D. Designing tasks for the communicative classroom. Cambridge: CUP, 1989.

ONESTI, C.; SQUARTINI, M. L'acquisizione della perifrasi progressiva in italiano L2: questioni metodologiche. In: CORINO, E.; MARELLO, C. (a cura di). V ALICO. Studi di lingnistica e didattica. Perugia: Guerra, 2009, 21-36.

PRABHU, N. S. Second language pedagogy. Oxford: OUP, 1987.

SABATINI, F. La storia dell'italiano nella prospettiva della corpus linguistics. In: Plenary Lectures, 2011, 31-37. Disponível em: $<$ https://euralex.org/wpcontent/themes/euralex/proceedings/Euralex\%202006/004_2006_V1_Fran cesco $\% 20$ SABATINI_La $\% 20$ Storia $\% 20$ dellitaliano $\% 20$ nella $\% 20$ Prospettiva $\% 20$ della\%20Corpus\%20Linguistics.pdf>. Acesso em: 20 dez. 2020.

SCARAMUCCI, M. V. R. CELPE-Bras: Porque um exame comunicativo. In: CUNHA, M. J.; SANTOS, P. (orgs.). Ensino e pesquisa em Português para estrangeiros. Universidade de Brasília: DF, 1996.

SCHMIDT, R. The role of consciousness in Second Language Learning. Applied Linguistics, v. 11, n. 2, 1990, 129-158.

- Awareness and Second Language Acquisition. Annual Review of Applied Linguistics, v. 13, 1993, 206-226.

- Deconstructing consciousness in search of useful definitions for Applied Linguistics. Alfa Review, v. 11, 1994, 11-26. 
SCHMIDT, R.; FROTA, S. Developing basic conversational ability in a second language: a case study of an adult learner of Portuguese. In: DAY, R. (ed.). Talking to learn: conversation in second language acquisition. Rowley, MA: Newbury House, 1986, 237-326.

SKEHAN, P. A cognitive approach to language learning. Oxford: Oxford University Press, 1998.

SWAIN, M. Three functions of output in second language learning. In: COOK, G.; SEIDLHOFER, B. (eds). Principle and practice in applied linguistics. Oxford: Oxford University Press, 1995, 125-144.

. The output hypothesis: theory and research. In: Hindel, E. (ed.), Handbook of research in second language teaching and learning. Yahweh, N.J: Lawrency Erlbaum Associates, 2005, 471-483.

Languaging, agency and collaboration in advanced second language learning. In: Byrnes, H. (ed.) Advanced language learning: the contributions of Halliday and Vygotsky. London, New York: Continuum, 2006, p. 96-108.

WILLIS, J. A. A framework for task-based learning. London: Longman, 1996.

XAVIER, R. P. Revisitando o conceito de tarefas comunicativas. Caderno de Letras - UFPel, n. 13, 2007, 35-46.

ZAGREBELSKY, M. L'introduzione della corpus linguistics o linguistica dei corpora, nelle università italiane: una ricostruzione personale dagli anni '60 a oggi. Quaderni del CIRSIL, v. 4, 2005, 203-213.

ZULOAGA, M. Connettivi avversativi nei testi scritti da apprendenti ispanofoni di italiano per il corpus VALICO. In: CORINO, E.; MARELLO, C. (a cura di). VALICO. Studi di linguistica e didattica. Perugia: Guerra, 2009, 179193. 